This is the post print version of the article, which has been published in Scandinavian Journal of Caring Sciences. 2018, 32(1), 241-252. http://dx.doi.org/10.1111/scs.12455

This document has been downloaded from TamPubutafi The Institutional Repository of University of Tampere

\title{
Women with vulvodynia: Awareness and knowledge of its care among student healthcare staff
}

Minna Törnävä PT, M.Sc, (PhD candidate) $)^{1,2}$, Meeri Koivula RN, PhD (Senior lecture) $)^{1}$, Mika Helminen M.Sc (Statistician) ${ }^{1,2}$, Tarja Suominen RN, PhD (Professor) ${ }^{1}$

${ }^{1}$ Faculty of Social Sciences, Health Sciences, University of Tampere, Tampere, Finland and ${ }^{2}$ Tampere University Hospital, Pirkanmaa Hospital District, Tampere, Finland

\section{Acknowledgements}

We would like to thank student healthcare staff who kindly participated in the study.

\section{Author contribution}

Minna Törnävä is the author of the paper. She was responsible for the conception, design, data analysis and drafting of the manuscript. Meeri Koivula and Tarja Suominen were responsible for the conception, design, data analysis, and critical revision of the manuscript, and for overall supervision. Mika Helminen was responsible for data analysis and statistical expertise.

\section{Ethical approval}

The study protocol was approved by the board of trustees of the student healthcare administrative units prior to the study.

\section{Funding}

This study was supported by the University of Tampere, School of Health Sciences, and by the Competitive State Research Financing of the Expert Responsibility area of Tampere University Hospital (9S069/9U060). No conflict of interest has been declared by the authors.

Correspondence to; Minna Törnävä, Tampere University Hospital, P.O. Box 2000, FIN-33521 Tampere, Finland: E-mail: tornava.minna.k@student.uta.fi or minna.tornava@pshp.fi 
Background: Many women with vulvodynia are women of fertile age, and this syndrome may cause many physical and psychosexual functional disorders. Women with vulvodynia often find that healthcare professionals seem to demonstrate a lack of awareness about the syndrome and its care. These issues have not been previously studied among student healthcare staff.

Aim: To investigate awareness and knowledge about vulvodynia and its care among staff in the student healthcare sector in Finland.

Method: The study design was cross-sectional. A survey instrument called 'Awareness and knowledge of vulvodynia and its care' was developed for this study and was used for data collection. The data were collected from a web-based survey conducted with student healthcare professionals $(N=191, n=79)$ in all 13 student healthcare units in Finland. Descriptive statistical methods were used to describe the connections between the factors associated with awareness of vulvodynia and its care. Ethical standards were followed throughout the study.

Results: The primary results of the study indicated that the respondents had somewhat good awareness of how to identify vulvodynia and somewhat poor awareness of the treatments for vulvodynia. Participants' awareness of the meaning of encountering patients, as well as the information and support they provided, were good. Based on the knowledge test, knowledge of vulvodynia and its care was estimated to be poor. The respondents' experience-based skills in treating vulvodynia and education about vulvodynia were mostly associated with better awareness and knowledge about vulvodynia and its care.

Conclusion: The student healthcare staff who meet and care for women of fertile age have irregular awareness and knowledge of vulvodynia and its care. The creation of educational programs to develop such awareness and knowledge is recommended to obtain a standard quality of care for all women with vulvodynia.

Keywords: Vulvodynia, Vulvar pain, Women's health, Awareness, Knowledge, Patient care management, Nursing, Student healthcare, Web-based survey 


\section{Introduction}

Vulvodynia, which involves the female reproductive system, represents both physical and psychosexual health concerns for women. However, women with this syndrome often find that it is misunderstood, misdiagnosed, mismanaged and ignored (1-3). Vulvodynia carries a heavy personal cost to patients $(1,4)$ and a significant financial cost to society (4), with women typically consulting over three physicians about pain $(5,6)$. It is important that healthcare professionals who meet women of reproductive age have sufficient awareness and knowledge of vulvodynia and its management. Early intervention to deal with the symptoms of vulvodynia in primary healthcare, such as student healthcare, may prevent sexual and reproductive health problems in young women $(1,7,8)$. Though there is some evidence regarding the knowledge of vulvodynia and its care among physicians (9-11), there is no such research in primary healthcare settings, such as among student healthcare staff who meet and care for nulliparous women.

\section{Background}

\section{Definition and aetiology of vulvodynia}

If a woman has vulvar pain that has no clear aetiology, it is usually called vulvodynia. The International Society for the Study of Vulvar Diseases (ISSVD) defines vulvodynia as chronic pain or discomfort involving the vulva for more than three months and for which no obvious aetiology can be found $(12,13)$. The term 'burning vulva syndrome' was coined by the ISSVD in 1975 (14). Nowadays, vulvodynia can be classified according to the anatomical site of the patient's pain. The pain may be localised to a specific area (localised vulvodynia) or all over the vulva (generalised vulvodynia). Vulvodynia can also be categorised based on whether a woman's pain is provoked or unprovoked $(7,15,16)$. Women with vulvodynia most often describe the quality of the pain as burning, rawness, stinging, tearing or irritation in the vulva area. Women may feel vulvodynia only during sexual intercourse, but it can also be triggered by nonsexual activities $(15,17)$. 
Localised, provoked vulvodynia is the most common form of the condition, with a prevalence of $16 \%$, and patients are usually young nulliparous women ( $<30$ years old $)$. These women experience vulvar pain through direct touch, such as sexual intercourse, tampon insertion or physical examination. Most women with vulvodynia complain of pain during sexual activities (dyspareunia) or of inability to have intercourse due to pain $(5,18)$. Localised, provoked vulvodynia is often associated with vaginismus: involuntary spasms of the pelvic floor muscles provoked by touch, which narrow or close the vaginal opening $(17,19)$. Generalised vulvodynia is less common, with a prevalence of $6-7 \%$. Those women feel the pain as a diffused, constant, burning or raw pain anywhere in the genital and/or pelvic area. The onset of generalised vulvodynia usually occurs in women at the age of 40 , but all ages can be affected $(15,20)$.

The prevalence of vulvodynia, or unexplained vulvar pain, in women has been investigated in the United States $(5,21,22)$, Portugal $(23)$ and Sweden $(24,25)$. These studies have shown the lifetime prevalence of unexplained vulvar pain to be between 8 and 16\%, and its incidence is thought to be increasing in young women. The onset of the pain symptoms usually occurs in young women between the ages of 18 and 25 . One study showed that $47-49 \%$ young Swedish women (between 13 and 22 years of age) had dyspareunia (26). Regarding race, American researchers found that Hispanic women had a higher risk of unexplained vulvar pain, but there was little difference in the risk between white and black women $(5,27)$. However, Reed et al. (2012) reported a higher prevalence of vulvodynia among white and Hispanic women when compared with black women (22). It is believed that vulvodynia's causes are multifactorial. Though the exact causes remain uncertain, researchers have isolated some possible causes for vulvodynia, including inflammation, genetic factors, hormonal factors and contributing psychosocial factors (27-29). Beginning the use of birth control pills at an early age has also been found to be related to increased sensitivity in the mucosa of vulvar vestibular area $(15,30,31)$. It has also been found also that experiencing severe pain at first tampon insertion is linked to a higher risk of reporting chronic 
dyspareunia (5,32). Musculoskeletal factors, particularly pelvic floor muscle dysfunction, are also commonly associated with in vulvodynia, especially among women with vaginismus $(33,34)$.

\section{Women's experiences with vulvodynia}

Women with vulvodynia experience this bodily pain syndrome not only physically, but also psychologically. Vulvar pain affects the way women experience their genitals and bodies overall. Because sexual organs are closely tied to gender, and therefore womanhood, women with this genital disorder often find that it affects their selfhood (35). Women with vulvodynia have reported a reduced quality of life, including anxiety and depression, as well as feelings of shame and guilt regarding the pain in their genital area (36-38). Because women with vulvodynia have challenges with or are unable to perform penetrative vaginal intercourse, they describe themselves as fake or inauthentic women, and as incomplete girlfriends or wives $(18,35,39)$. Indeed, vulvodynia is reflected in couple's relationships. Not only does sexual pain shape couples' sex life $(18,35,39)$, but it also may affect a relationship's stability and shape (39). Vulvodynia in a couple may strain the relationship, but its effect may also be neutral, and it can even be empowering, depending on the women and their partners' pain behaviour models (39-41). Some women choose to live without a partner because of the sexual pain, as they feel that life is easier without being in a couple (39).

\section{Treatment of vulvodynia}

Evidence regarding the care of vulvodynia is mostly based on clinical experience, descriptive studies and reports of experts' committees, because there have been few randomised trials $(16,42,43)$. Counselling by healthcare personnel about gentle self-care of the vulva area is essential to minimise vulva irritation $(15,42,44)$. Also, counselling regarding the use of desensitisation and dilatation exercises at home have been found to be beneficial in reducing vulvar pain $(16,45)$. 
Pelvic floor physiotherapy has been shown to reduce pain in women with vulvodynia. Biofeedback helps women develop their ability to self-regulate, thereby better controlling the reactions of the pelvic floor muscle and reducing the pain in the vulva $(19,46,47)$. Physiotherapy modalities also include internal and external myotrigger-point release manipulation, transcutaneous electrical stimulation and instructions for self-care with vulvodynia $(16,47,48)$.

Psychosexual interventions, like cognitive-behavioural therapy or sex therapy, have also been shown to be efficacious in reducing vulvar pain and improving associated psychosexual outcomes women with vulvodynia (49). The goals of psychosexual interventions are to help women to view their vulvar pain as a multidimensional problem that involves emotions, behaviours and couple interactions. In therapy, women and sometimes their partners try to modify some of the factors described above to increase adaptive coping, decrease pain intensity and improve the quality of sexual functions $(49,50)$. If a woman with vulvodynia has a partner, couple therapy is recommended $(50,51)$. A partner's behavioural reaction to a women's pain has been shown to have an impact on the intensity of pain and her reaction to the pain $(40,41)$.

Medical interventions, like medications used to treat vulvodynia include topical, oral and injectable medical substances. Commonly prescribed medications include local anaesthetics, which can be used before intercourse or overnight $(16,42,47)$. If conservative treatments have not been useful and the pain is localised provoked vulvodynia, a surgery called vestibulectomy may be an effective treatment (52).

Although optimal evidence regarding specific treatment options is still unavailable, an individualised, multidisciplinary approach is recommended to address both the physical and psychosexual aspects of vulvodynia $(16,17,42)$. Women who have participated in such care have generally perceived it as holistically beneficial. They have reported feeling safe, empowered and supported by a team of many professionals. A team approach has been shown to increase women's knowledge of the syndrome and to help them gain the skills they need to address their pain. They 
have reported reduced vulvar pain when interventions complemented one other. Moreover, the multidisciplinary approach encourages women to take the responsibility for her own care (1-3).

\section{Knowledge of vulvodynia and its care}

Existing research about knowledge of vulvodynia and its treatment among healthcare professionals has focused on the perspectives of either women with vulvodynia or physicians. The few scientific studies investigating women's experiences of the care they received have reported that healthcare staff's knowledge was inadequate from the patients' viewpoint $(1,4,8)$. However, in the experience of women with vulvodynia, the syndrome is often misunderstood, misdiagnosed, mismanaged and ignored (1-3). An estimated $40 \%$ of women seeking treatment fail to receive help, and this estimate may be conservative $(5,29)$. Harlow and Stewart (2003) found that $60 \%$ of women who sought help for their syndrome saw three or more doctors, many of whom could not provide a diagnosis (5).

Toeima and Nieto (2010), who examined this issue from the perspective of medical practitioners, had similar results (10): they found that junior gynaecologists had insufficient understanding of vulvodynia and its management. Phillips et al. (2013) reported a slightly better awareness among obstetricians and gynaecologists, who were moderately comfortable with providing care for vulvodynia patients (9). An earlier study (11) found that physicians who treated women with chronic vulvar pain had a good level of knowledge, allowing them to evaluate the condition and use different treatments. Because of their solid knowledge of vulvodynia and its care, the physicians were able to recommend a variety of self-care modifications to women with vulvodynia and use a wide variety of therapies for different variants of vulvodynia.

To date, no study on this topic has been conducted from the perspective of primary healthcare, such as student healthcare professionals. In Finland, these healthcare providers usually have first contact with young women who have problems with intimacy. Women with vulvodynia have reported negative experiences with Finnish primary healthcare in terms of knowledge of 
vulvodynia and its care (1). There is a need, therefore, to measure awareness and knowledge of vulvodynia and its care among student healthcare professionals who meet and provide care to young women.

\section{Methods}

\section{Aims}

The aims of this study are to describe the student healthcare staff's awareness and knowledge of vulvodynia and its care, as well as the factors associated with this issue.

\section{Design and sample}

The study design was national, descriptive and cross-sectional. Student healthcare is part of primary healthcare in Finland. Student healthcare staff, who serve higher education students, were chosen as the target group because they meet women of reproductive age. The study was conducted nationwide in all 13 student healthcare units in Finland, which serve higher education students over 18 of age. One unit was used to run a pilot survey. Student healthcare unit professionals $(N=191)$, such as public health nurses, registered nurses, physiotherapists, psychologists and physicians, in the general and mental healthcare fields of the remaining 12 units were invited to participate in the survey via an email information letter that detailed the study's objectives and explained that completing the web-based survey implied their consent. The information letter also stated that participation was voluntary, and the survey was completely anonymous (53). The survey was carried out between February and April 2015. The data were collected from a web-based questionnaire. A hyperlink was included in the information letter sent to the respondents, which allowed the healthcare professionals to respond voluntarily to an anonymous web-based survey. The researcher wrote an email reminder letter about the survey, which the nurses in charge of the units sent twice, on the second and fourth weeks, respectively, after the survey started. 


\section{Instrument}

The web-based questionnaire consisted of individual background factors and 'The awareness and knowledge of vulvodynia and its care' (AKVDC) survey instrument developed by authors (Table 1). This new AKVDC survey instrument was created to assess the healthcare staff's awareness and knowledge of vulvodynia and its care. The AKVDC survey instrument included two main parts: 'Awareness of vulvodynia and its care' (Part 1) and 'Knowledge about vulvodynia and its care' (Part 2). Part 1 was developed based on patient-related qualitative research findings on the care experiences of women with vulvodynia $(1,39)$, while Part 2 was based on previous literature about vulvodynia $(7,27,28)$ and its management $(15,16,19)$.

Part 1 of the AKVDC instrument covered four main dimensions of awareness: how to identify vulvodynia, the treatments for vulvodynia, the significance of encountering vulvodynia patients and the significance of providing information and support to vulvodynia patients. A 6point Likert scale, ranging from 1 (completely disagree) to 6 (completely agree) or ranging from 1 (I know it remarkably poorly) to 6 (I know it remarkably well), was used to measure the participants' awareness. Awareness of how to identify vulvodynia was measured with 14 items concerning the identification of symptoms of vulvodynia. For example, participants were asked to react to the following claim: 'Vulvodynia may rule out intercourse'. Awareness of the treatments for vulvodynia was measured with 13 items concerning the treatment options of vulvodynia, such as self-care, and guidelines for the treatment. For instance, for this dimension, respondents responded to the following item: 'I know the content of nursing in the treatment of vulvodynia'. Awareness of the significance of encountering vulvodynia patients was measured by 15 items regarding the meaning of encountering patients at a reception situation. For example, one item for this dimension is: 'I know how at a reception situation I encounter sexual problems of women with vulvodynia'. Awareness of the significance of providing information and support to vulvodynia patients was measured with 24 claims based on patient reports concerning the value of receiving information and 
support, such as: 'Providing information to women about vulvodynia motivates them to self-treat' (Table 1).

Part 2 of the AKVDC instrument covered the participants' knowledge through 20 items on vulvodynia and its care. This part of the instrument was used to measure the participants' knowledge about the definition $(12,14,15)$, aetiology $(7,28,54)$ and management options $(16,17$, 44) of vulvodynia based on evidence. This knowledge test used three options for the answers: true, false and unsure. An example of one item in this test is: 'Psychosexual therapies are not used in the treatment of vulvodynia' (Table 1).

[Table 1 about here]

\section{Data analysis}

The data were analysed using IBM SPSS Statistics 23 for Windows (IBM 2015). The Cronbach's alpha score was used to calculate whether the aggregate of Part 1 of the AKVDC instrument was valid. The items in Part 1 were rated using a 6-point Likert scale. The subscale scores were obtained by summing the responses for each item and calculating the mean response. The average scores of the subscales created the total score for awareness, which was divided as follows: 1.00 1.82 (remarkably poor awareness), 1.83-2.66 (poor awareness), 2.67-3.50 (somewhat poor awareness), 3.51-4.34 (somewhat good awareness), 4.35-5.18 (good awareness) and 5.19-6.00 (remarkably good awareness).

For the purpose of calculating the participants' knowledge of the items in Part 2 of the AKVDC instrument, all correct answers were recorded as equal to 1; all incorrect or unsure answers were recoded as 0 . The data from the 20 questions were analysed by totalling the score for all the answers from each participant, resulting in an individual knowledge score between 0 and 20 .

Descriptive statistics using absolute (n) and relative (\%) frequencies were applied to analyse the categorical data, while the mean, median $(\mathrm{Md})$, quartile (Q1, Q3) and interquartile range (IQR) were used to calculate the respondents' awareness and knowledge of vulvodynia and its care. For 
the knowledge test, the mean of the correct answers was used to calculate the respondents' knowledge of vulvodynia and its care. Non-parametric tests were used because of the small sample size and because the variables were not normally distributed. The Mann-Whitney U test was used for the comparison of variables with two categories. The Kruskal-Wallis test was used to analyse the connections among variables with three categories. A $p$-value of $<0.05$ was considered statistically significant.

\section{Validity and Reliability}

The AKVDC instrument's content and face validity were tested by an independent panel of multiprofessional healthcare staff $(\mathrm{N}=9)$ composed of uro/gynaecological nurses, pelvic floor physiotherapists, sex counsellors and gynaecologists. They commented on the structure, phrasing, clarity, comprehensibility, relevance and assessment scale of the instrument. Based on their work experience with vulvodynia patients, the instrument was modified as appropriate.

The reliability test for Part 1 of the AKVDC instrument was conducted using a pilot group of student healthcare staff $(n=34)$. The pilot participants were asked to complete the questionnaire and give feedback about unclear questions in the instrument. Internal reliability was tested by calculating the Cronbach's alpha $(\alpha)$ for each subscale. We found acceptable internal consistency $(\alpha$ $>0.70)$ for all subscales except the 'awareness of the significance of encountering patients' $(\alpha=$ 0.69). Thus, we clarified a few questions under the dimension of awareness. Prior to the actual study with student healthcare staff, the instrument was modified and clarified based on the pilot study.

In this study, all four subscales under Part 1 showed acceptable internal consistency (Table 1). The Cronbach's alpha values for the subscales of the awareness dimensions were as follows: how to identify vulvodynia $(\alpha=0.83)$, treatments for vulvodynia $(\alpha=0.80)$, the significance of encountering patients $(\alpha=0.89)$ and the significance of providing information and support to patients $(\alpha=0.91)$. 


\section{Results}

Participants' characteristics

Seventy-nine healthcare professionals in the student healthcare field agreed to participate, and there was a $41.4 \%$ response rate. The majority of the participants were female (94\%) and public health nurses $(42 \%)$ who worked under a regular contract (86\%). Their average age was 46 (range: $27-$ 65). Their length of work experience in healthcare ranged between 1 and 40 years (mean: 20 years).

Eleven participants had specialised in sexology. A third of the participants had attended one or more lectures about vulvodynia. The majority of the participants $(63 \%)$ met with patients with vulvodynia — or those suspected to have the condition—less often than once a month. Based on their own experience, the majority $(76 \%)$ of the participants rated themselves poorly regarding their skills in providing care for vulvodynia patients. Similarly, most $(81 \%)$ reported that their skills were poor with regard to taking care of both vulvodynia patients and the patients' partners. Over half of the participants (54\%) claimed to have good, experience-based skills in discussing intimate issues in a natural manner during their encounters with patients (Table 2).

The highest response rate was among public health nurses; thirty-three of 52 public health nurses $(64 \%)$ participated in the survey. Among the physiotherapists $(n=9)$, the response rate was 44\%. Among the physicians $(n=62)$ and other nursing/therapy staff participants $(n=14)$, the average response rate was $36 \%$. Most non-participants of the student healthcare unit professionals $(N=191)$ were psychologists and registered nurses; only 11 of 40 psychologists and 4 of 14 registered nurses participated in the survey, with an average response rate of $28 \%$.

[Table 2 about here]

Part 1 of the AKVDC: Awareness of Vulvodynia and Its Care

Awareness of how to identify vulvodynia among the participants was somewhat good $(\mathrm{Md}=3.86$ out of 6.00) among the student healthcare staff. Of the background factors, the respondents' 
specialisation in sexology, participation in one or more lectures on vulvodynia and frequency of meetings with vulvodynia patients were statistically significantly associated with awareness of how to identify of vulvodynia. Moreover, all experienced-based skills, such as providing care to vulvodynia patients, providing care for vulvodynia couples and discussing intimate matters, were statistically significantly associated with the awareness of how to identify vulvodynia. The awareness of participants with a specialisation in sexology was good. Additionally, the participation of respondents in lecture/s on vulvodynia was positively associated with their awareness of this dimension. The participants who had not met with vulvodynia patients rated their awareness as somewhat poor, whereas their colleagues who had met with vulvodynia patients less often or least once a month rated their awareness as somewhat good. Based on their experiences, the participants who regarded themselves as having good skills in caring for vulvodynia patients or vulvodyniaimpacted couples rated their awareness of how to identify vulvodynia as good. Participants who rated their skills as poor in terms of being able to discuss intimate issues naturally also rated their awareness as somewhat poor (Table 3).

Awareness of treatments for vulvodynia among the participants was somewhat poor $(\mathrm{Md}=$ 3.23 out of 6.00). Of the background factors, age, work experience, specialisation in sexology, participation in one or more lectures on vulvodynia, frequency of meetings with vulvodynia patients and experienced-based skills in caring for vulvodynia patients and couples and in discussing intimate issues in a natural manner were statistically significantly associated with participants' awareness of treatments for vulvodynia. Participants aged between 27 and 40 rated their awareness of treatment as somewhat good, which was higher than the self-ratings of their older colleagues. Participants with a specialisation in sexology rated their awareness as somewhat good, whereas those with no specialisation in sexology rated their awareness as somewhat poor. Additionally, the participation of respondents in one or more lectures on vulvodynia was positively associated with their awareness of how to identify vulvodynia when compared to the awareness of participants who 
did not attend such lectures. Participants who had not met with vulvodynia patients or who met with vulvodynia patients less often than once a month rated their awareness of treatments for vulvodynia as poor. Based on their experience, the participants who perceived themselves as having good skills in providing care for vulvodynia patients or couples rated their awareness of the care for vulvodynia patients as somewhat good. Participants who claimed to have good skills in discussing intimate issues naturally rated their awareness as somewhat good (Table 3).

Awareness of the significance of encountering vulvodynia patients among the participants was good ( $\mathrm{Md}=5.00$ out of 6.00). Of the background factors, only skills in caring for vulvodynia patients and couples and discussing intimate issues naturally were statistically significantly associated with awareness of the meaning of encountering patients. Based on their experience, participants who reported having good skills in taking care of vulvodynia patients or couples rated their awareness of the meaning of encountering patients as remarkably good. Likewise, participants who claimed to have good skills in discussing intimate issues naturally rated their awareness as remarkably good (Table 3).

Awareness of the significance of providing information and support to vulvodynia patients among all participants was good $(\mathrm{Md}=5.17$ out of 6.00$)$. None of the background factors were associated with awareness of this dimension (Table 3).

[Table 3 about here]

\section{Part 2 of the AKVDC: Knowledge of Vulvodynia and Its Care}

The participants' knowledge of vulvodynia and its care was assessed with a 20 -item test. One participant answered all items correctly. Half or more of the questions were correctly answered by 37 participants $(46.9 \%)$. The mean of the correct answers for the 20 items across the entire dataset was 9.34. All other factors except 'experienced-based skills in naturally discussing intimate issues', were statistically significantly associated with knowledge of vulvodynia and its care. Participants aged 54-65 had higher knowledge scores than those of the younger age groups (mean $=11.57$ vs. 
8.35 and 7.88 , respectively). Similarly, the participants with $28-40$ years of work experience had higher knowledge scores $($ mean $=11.41)$ than those with $15-27$ years $($ mean $=8.46)$ or $1-14$ years $($ mean $=8.04)$ of work experience. The physicians scored higher on knowledge than the nursing and therapy staff (mean $=11.27$ vs. 8.60 , respectively). Participants who had specialised in sexology scored higher on knowledge than those without the specialisation (mean $=12.73$ vs. 8.79 , respectively). Likewise, participants who had attended one or more lectures on vulvodynia had higher knowledge scores than those who had not attended any lectures (mean $=11.46$ vs. 8.30, respectively). Participants who held at least one meeting per month with vulvodynia patients had higher knowledge scores $($ mean $=12.67)$ than those who met with patients less often than once a month $($ mean $=9.18)$ or never $($ mean $=6.36)$. The participants with good, experienced-based skills in caring for vulvodynia patients obtained higher knowledge scores than those who had poor skills $($ mean $=12.32$ vs. 8.40$)$. Participants with good, experienced-based skills in caring for vulvodynia couples had higher knowledge scores than those with poor skills (mean $=12.07$ vs. 8.70 , respectively) (Table 4).

[Table 4 about here]

\section{Discussion}

To the best of our knowledge, this is the first study to examine the awareness and knowledge of vulvodynia and its care that has involved primary healthcare providers. In this case, we included student healthcare unit workers and other healthcare professionals, such as public health nurses, registered nurses, psychologists and physiotherapists, rather than only studying physicians. Unfortunately, the response rate was low, especially among psychologists. Notably, in most of the reports generated by expert committees and in treatment guidelines for vulvodynia, psychosexual interventions were recommended as one method of treatment $(16,42,49)$. This may cause healthcare professionals in Finland to consider vulvodynia as more of a somatic rather than a psychological disorder and could explain why psychologists were not motivated to respond to the 
survey. The public health nurses responded commendably to the survey. They likely find it important because, in Finland, they tend to be the first healthcare workers to encounter women with intimate problems.

This study identified several areas for development among student healthcare professionals regarding this subject. In particular, we found that their awareness of treatments for vulvodynia was somewhat poor. Likewise, their knowledge of vulvodynia and its care, as measured through a knowledge test, was calculated as poor. Although the findings showed good awareness of the significance of encountering and of providing information and support to vulvodynia patients, we must conclude that the participants had varied levels of awareness and knowledge of vulvodynia and its care.

In examining the background factors related to awareness of vulvodynia and its care, a specialisation in sexology was associated with better awareness of how to identify and treat vulvodynia, as was participation in vulvodynia lectures. Attending these lectures was also associated with better knowledge of vulvodynia and its care. We can therefore conclude that even short courses or education on this subject and on sexual health will enhance staff's awareness and knowledge of how to identify and manage vulvodynia. Several studies recommend a multidisciplinary approach to the care of vulvodynia as most effective strategy $(15,42,44)$. In this light, education programs for providers should be organised multi-professionally.

Based on the student healthcare professionals' experience and specialty, good skills in providing care to vulvodynia patients or couples were associated with a better awareness of how to identify and treat vulvodynia, as well as the significance of encountering patients. These factors were also connected to better knowledge of vulvodynia and its care. This finding was expected, since sufficient awareness of the syndrome would be a precondition for learning the relevant skills. Moreover, good, experienced-based skills in discussing intimate issues naturally were associated with the abovementioned dimensions of awareness. Possibly due to the naturalness of these 
conversations, healthcare professionals' awareness increased through patient-oriented communication (55). In a care situation, a calm, frank discussion between a vulvodynia patient and a healthcare professional about this intimate problem has been found to foster a sense of trust in women patients. In turn, this sense of trust facilitates a more detailed description of her vulvodynia symptoms and intimate problems $(1,55)$. It is also found that women with newly diagnosed vulvodynia are open to counselling to address the psychosexual aspects of their vulvar pain, and they report that it has helped them to cope with intimacy problems (56).

Participants who were 27-40 years old were more aware of treatment options for vulvodynia than older age groups. These younger practitioners are possibly more accustomed to searching international, evidence-based information on the syndrome, for which no national treatment recommendations or clinical guidelines have been issued so far. A few international clinical guidelines for the treatment of vulvodynia have been established $(16,19,42)$. Another reason that younger participants may be more informed may be related to the fact that they are the same age as their potential patients with vulvodynia. They may have experience with this syndrome through their circle of acquaintances, or they may be interested in intimacy problems that may affect women's lives at their age (55). Likewise, participants with fewer than 15 or more than 27 years of work experience in healthcare were more aware of treatments for vulvodynia than their colleagues with 15-27 years of work experience. Most of those who had fewer than 15 years of experience were younger healthcare providers, so this association may be explained in the same way as the previous result. Interestingly, participants who had over 27 years of work experience and were over 53 years old had better knowledge scores on the knowledge test than younger practitioners or those with less work experience. Participants who have worked the longest in the healthcare sector may have acquired experiential awareness of treatments for vulvodynia and knowledge of vulvodynia and its care. 
In the present study, almost $20 \%$ of participants had never met or identified a woman with vulvodynia. Naturally, the participants who held meetings with vulvodynia patients at least once a month were more aware of how to identify and treat it. However, their awareness of how to identify the condition was better than their awareness of its treatment. This study's results showed that awareness of treatment for vulvodynia was the poorest dimension of awareness of this syndrome and its care. Likewise, the knowledge test showed that knowledge of the care methods was the poorest dimension. Vulvodynia is a complex pain syndrome that lacks clarity regarding its treatment and care, which may explain why treatment competence was the poorest dimension of awareness and knowledge. Current evidence regarding the care of vulvodynia is mostly based on clinical experience, descriptive studies and reports from expert committees; few randomised or longitudinal trials have been conducted $(16,17,42)$. It is possible that, after vulvodynia has been identified, the patient is directed from student healthcare to specialist healthcare because of the practitioners' lack of awareness and knowledge of its treatment. However, once the condition has been identified by a physician, patients want to receive treatment for its symptoms or at least some information about vulvodynia and its self-care methods $(1,8)$. In student healthcare settings, public health nurses could provide first-line education about the vulva and counselling regarding its gentle care. Psychologists could also provide information to help women view vulvodynia as a multidimensional problem that involves emotions, behaviours and a couple's interactions. Women have been found to appreciate a multi-professional care setting, which makes it easy to understand their own situation and to control their self-care (1-3). It is recommended that treatment of vulvodynia patients be multidisciplinary $(16,57,58)$.

Some qualitative studies have examined women's experiences with the care they have received for vulvodynia. These studies have shown both positive and negative treatment experiences. Being diagnosed with vulvodynia is the first step in a patient's adoption of and commitment to treatment $(1,2,8)$. A delayed diagnosis and treatment of vulvodynia has been 
reported to adversely affect sexual health, as well as having a negative impact on mental health, self-esteem and emotions $(1,8)$. It has also been found that starting treatment eases anxiety and increases awareness of vulvodynia for both the patient and her partner (1, 3, 39). Dismissive, untrustworthy or unskilled encounters with healthcare staff have been shown to increase the patient's levels of shame, anxiety, despair and even disbelief in her own symptoms $(1,8)$. However, in the present study, the student healthcare providers' self-assessment of their awareness of the significance of encountering a vulvodynia patient as good.

In Finland, young women's first contact with intimate problems usually happen in a primary healthcare setting. In this case, student healthcare, as the primary healthcare provider for students in higher education, has important role in early diagnosis and intervention with vulvodynia. It is important that public health nurses and other primary care providers provide counselling and selfcare options to patients as a first-line treatment option $(16,42,44)$. It is essential to keep in mind that the student healthcare sector's early intervention in treating vulvodynia symptoms might reduce or even prevent sexual and reproductive health problems, as well as other psychiatric effects and psychological and physical drawbacks related to the syndrome. Likewise, early diagnosis and intervention with first care options in student healthcare may also be profitable to patients themselves and to society. Based on previous evidence and that of the present study, it is important to consider developing healthcare staff's awareness and knowledge of vulvodynia and its care, particularly regarding the abovementioned first-line treatment options.

\section{Limitations}

Some limitations of this study should be acknowledged. First, the AKVDC instrument is new, and it has only been used in a pilot test and in this study. The validity and reliability of this instrument warrant further testing with larger samples of healthcare professionals. Second, participation was voluntary, with a response rate of $41 \%$. It is possible that the recruited participants were already focused on the sexual health issues of young students, leading to the potential for selection bias in 
the results. Third, reliance on self-reported measures might have led to common method bias, inflating the findings. Finally, the study's cross-sectional design could have prevented the inference of any causal relationships among the variables. Despite these drawbacks, this study provides some insights into the student healthcare staff's levels of awareness and knowledge of vulvodynia and its care.

\section{Conclusion}

The student healthcare staff who care for nulliparous women have varied levels of awareness and knowledge of vulvodynia and its care. As a consequence, they are not offering competent care and support to young women in need. However, primary care providers, such as public health nurses, could play a much more important role in counselling patients regarding self-care options, such as vulvar care measures, as first-line treatment options. Healthcare staff need to become better educated and give more attention to the awareness and knowledge of how to treat vulvodynia to prevent the sexual and reproductive health problems it causes in young women. Student healthcare centre workers as well primary healthcare providers play an important role in the early diagnosis and implementation of first-line interventions for vulvodynia. The creation of educational programs for vulvodynia and its first-line treatment options to increase student healthcare staff awareness and knowledge of vulvodynia and its care is recommended to establish a standard quality of care for women with vulvodynia in all student healthcare units.

\section{References}

1 Törnävä M, Koivula M, Suominen T. Vulvodyniaa sairastavien naisten hoitokokemuksia. (Care experiences of the women with vulvodynia). Tutkiva hoitotyö

2 Sadownik LA, Seal BN, Brotto LA. Provoked vestibulodynia-women's experience of participating in a multidisciplinary vulvodynia program. J Sex Med 2012; 9: 1086-1093.

3 Munday P, Buchan A, Ravenhill G, Wiggs A, Brooks F. A qualitative study of women with vulvodynia: II. Response to a multidisciplinary approach to management. J Reprod Med 2007; 52: 19-22. 
4 Gordon AS, Panahian-Jand M, Mccomb F, Melegari C, Sharp S. Characteristics of women with vulvar pain disorders: responses to a Web-based survey. J Sex Marital Ther 2003; 29: 45-58.

5 Harlow BL, Stewart EG. A population-based assessment of chronic unexplained vulvar pain: have we underestimated the prevalence of vulvodynia?. J Am Med Womens Assoc 2003; 58: 82-88.

6 Nguyen RHN, Ecklund AM, Maclehose RF, Veasley C, Harlow BL. Co-morbid pain conditions and feelings of invalidation and isolation among women with vulvodynia. Psychology Health \& Medicine 2012; 17: 589-598.

7 Sadownik LA. Etiology, diagnosis, and clinical management of vulvodynia. International Journal of Women's Health 2014; 6: 437-449.

8 Buchan A, Munday P, Ravenhill G, Wiggs A, Brooks F. A qualitative study of women with vulvodynia: I. The journey into treatment. J Reprod Med 2007; 52: 15-18.

9 Phillips A, Large E, Bird M, Hitt W, Eastham D, Pulley L, et al. Vulvodynia in Arkansas: A Survey of Arkansas Gynecologists' Practice Experience and Management of Vulvar Pain. $J$ Ark Med Soc 2013; 109: 206-208.

10 Toeima E, Nieto J. Junior doctors' understanding of vulval pain/vulvodynia: a qualitative survey. Arch Gynecol Obstet 2011; 283: 101-104.

11 Updike GM, Wiesenfeld HC. Insight into the treatment of vulvar pain: a survey of clinicians. Am J Obstet Gynecol 2005; 193: 1404-1409.

12 ISSVD. International Society for the Study of Vulvar Diseases. 2016; www.issvd.org (last accessed 3 October 2016).

13 Bornstein J, Goldstein AT, Stockdale CK, Bergeron S, Pukall C, Zolnoun D, et al. 2015 ISSVD, ISSWSH and IPPS Consensus Terminology and Classification of Persistent Vulvar Pain and Vulvodynia. Obstet Gynecol 2016; 127: 745-751.

14 Haefner HK. Report of the International Society for the Study of Vulvovaginal Disease terminology and classification of vulvodynia. J Low Genit Tract Dis 2007; 11: 48-49.

15 Danby CS, Margesson LJ. Approach to the diagnosis and treatment of vulvar pain. Dermatologic Therapy 2010; 23: 485-504.

16 Nunns D. Mandal D. Byrne M. McLelland J. Rani R. Cullimore J. Bansal D. Brackenbury F. Kirtschig G. Wier M. British Society for the Study of Vulval Disease (BSSVD) Guideline Group. Guidelines for the management of vulvodynia. Br J Dermatol 2010; 162: 11801185.

17 Andrews JC. Vulvodynia interventions - systematic review and evidence grading. Obstet Gynecol Surv 2011; 66: 299-315.

18 Groven KS, Raheim M, Hakonsen E, Haugstad GK. "Will I ever be a true woman?" An exploration of the experiences of women with vestibulodynia. Health Care Women Int 2016; 37: 818-835.

19 Melnik T, Hawton K, McGuire H. Interventions for vaginismus. Cochrane Database of Systematic Reviews 2012; 12: 001760.

20 Harlow BL, Wise LA, Stewart EG. Prevalence and predictors of chronic lower genital tract discomfort. Am J Obstet Gynecol 2001; 185: 545-550.

21 Harlow BL, Kunitz CG, Nguyen RH, Rydell SA, Turner RM, MacLehose RF. Prevalence of symptoms consistent with a diagnosis of vulvodynia: population-based estimates from 2 geographic regions. Am J Obstet Gynecol 2014; 210: 40.e1-40.e8.

22 Reed BD, Harlow SD, Sen A, Legocki LJ, Edwards RM, Arato N, et al. Prevalence and demographic characteristics of vulvodynia in a population-based sample. Am J Obstet Gynecol 2012; 206: 170.e1-170.e9.

23 Vieira-Baptista P, Lima-Silva J, Cavaco-Gomes J, Beires J. Prevalence of vulvodynia and risk factors for the condition in Portugal. Int J Gynaecol Obstet 2014; 127: 283-287. 
24 Danielsson I, Sjoberg I, Stenlund H, Wikman M. Prevalence and incidence of prolonged and severe dyspareunia in women: results from a population study. Scand J Public Health 2003; 31: 113-118.

25 Danielsson I, Sjoberg I, Stenlund H, Wikman M. Samlagssmärta hos kvinnor vanligt, inte minst hos yngre. Smärtanamnes och kvinnans alder ger god vägledning för diagnos. (Dyspareunia in women is common, particularly in younger women. Pain history and the women's age provide valuable clues for diagnosis). Lakartidningen 2003; 100: 2128-2132.

26 Elmerstig E, Wijma B, Swahnberg K. Young Swedish women's experience of pain and discomfort during sexual intercourse. Acta Obstet Gynecol Scand 2009; 88: 98-103.

27 Reed BD, Legocki LJ, Plegue MA, Sen A, Haefner HK, Harlow SD. Factors associated with vulvodynia incidence. Obstet Gynecol 2014; 123: 225-231.

28 Bohm-Starke N. Medical and physical predictors of localized provoked vulvodynia. Acta Obstet Gynecol Scand 2010; 89: 1504-1510.

29 Goldstein AT, Burrows L. Vulvodynia. J Sex Med 2008; 5: 5-14.

30 Goldstein AT, Belkin ZR, Krapf JM, Song W, Khera M, Jutrzonka SL, et al. Polymorphisms of the androgen receptor gene and hormonal contraceptive induced provoked vestibulodynia. J Sex Med 2014; 11: 2764-2771.

31 Greenstein A, Ben-Aroya Z, Fass O, Militscher I, Roslik Y, Chen J, et al. Vulvar vestibulitis syndrome and estrogen dose of oral contraceptive pills. J Sex Med 2007; 4: 1679-1683.

32 Landry T, Bergeron S. How young does vulvo-vaginal pain begin? Prevalence and characteristics of dyspareunia in adolescents. J Sex Med 2009; 6: 927-935.

33 Reissing ED, Brown C, Lord MJ, Binik YM, Khalife S. Pelvic floor muscle functioning in women with vulvar vestibulitis syndrome. J Psychosom Obstet Gynaecol 2005; 26:107-113.

34 Reissing ED, Binik YM, Khalife S, Cohen D, Amsel R. Vaginal spasm, pain, and behavior: an empirical investigation of the diagnosis of vaginismus. Arch Sex Behav 2004; 33: 5-17.

35 Kaler A. unreal women: sex, gender, identity and the lived experience of vulvar pain. Feminist Review 2006; 82: 50-75.

36 Desrochers G, Bergeron S, Landry T, Jodoin M. Do psychosexual factors play a role in the etiology of provoked vestibulodynia? A critical review. J Sex Marital Ther 2008; 34: 198 226.

37 Khandker M, Brady SS, Vitonis AF, Maclehose RF, Stewart EG, Harlow BL. The influence of depression and anxiety on risk of adult onset vulvodynia. J Womens Health 2011; 20: 1445-1451.

38 Ehrstrom S, Kornfeld D, Rylander E, Bohm-Starke N. Chronic stress in women with localised provoked vulvodynia. J Psychosom Obstet Gynaecol 2009; 30: 73-79.

39 Törnävä M, Koivula M, Suominen T. Naisten kokemuksia vulvodynian vaikutuksesta parisuhteeseen. (Women's experiences the effects of vulvodynia on the pair relationship). Hoitotiede 2013; 25: 241-252.

40 Jodoin M, Bergeron S, Khalife S, Dupuis M, Desrochers G, Leclerc B. Male partners of women with provoked vestibulodynia: attributions for pain and their implications for dyadic adjustment, sexual satisfaction, and psychological distress. J Sex Med 2008; 5: 2862-2870.

41 Desrosiers M, Bergeron S, Meana M, Leclerc B, Binik YM, Khalife S. Psychosexual characteristics of vestibulodynia couples: partner solicitousness and hostility are associated with pain. J Sex Med 2008; 5: 418-427.

42 ASCCP. Committee Opinion No 673: Persistent Vulvar Pain. Obstet Gynecol 2016; 128 : e78-84.

43 De Andres J, Sanchis-Lopez N, Asensio-Samper JM, Fabregat-Cid G, Villanueva-Perez VL, Monsalve Dolz V, et al. Vulvodynia-An Evidence-Based Literature Review and Proposed Treatment Algorithm. Pain Practice 2016; 16: 204-236. 
44 Cox KJ, Neville CE. Assessment and management options for women with vulvodynia. $J$ Midwifery Womens Health 2012; 57: 231-240.

45 Lindstrom S, Kvist LJ. Treatment of Provoked Vulvodynia in a Swedish cohort using desensitization exercises and cognitive behavioral therapy. BMC Womens Health 2015; 15: 108/1-9.

46 Bergeron S, Binik YM, Khalife S, Pagidas K, Glazer HI, Meana M, et al. A randomized comparison of group cognitive - behavioral therapy, surface electromyographic biofeedback, and vestibulectomy in the treatment of dyspareunia resulting from vulvar vestibulitis. Pain 2001; 91: 297-306.

47 Morin M, Dumoulin C, Bergeron S, Mayrand M, Khalife S, Waddell G, et al. Randomized clinical trial of multimodal physiotherapy treatment compared to overnight lidocaine ointment in women with provoked vestibulodynia: Design and methods. Contemporary Clinical Trials 2016; 46: 52-59.

48 Murina F, Graziottin A, Felice R, Radici G, Tognocchi C. Vestibulodynia: synergy between palmitoylethanolamide + transpolydatin and transcutaneous electrical nerve stimulation. $J$ Low Genit Tract Dis 2013; 17: 111-116.

49 Bergeron S, Likes WM, Steben M. Psychosexual aspects of vulvovaginal pain. Best Practice \& Research in Clinical Obstetrics \& Gynaecology 2014; 28: 991-999.

50 Davis SN, Bergeron S, Sadikaj G, Corsini-Munt S, Steben M. Partner behavioral responses to pain mediate the relationship between partner pain cognitions and pain outcomes in women with provoked vestibulodynia. Journal of Pain 2015; 16: 549-557.

51 Corsini-Munt S, Bergeron S, Rosen NO, Steben M, Mayrand M, Delisle I, et al. A comparison of cognitive-behavioral couple therapy and lidocaine in the treatment of provoked vestibulodynia: study protocol for a randomized clinical trial. Trials $2014 ; 15$ : 506/1-11.

52 Tommola P, Unkila-Kallio L, Paavonen J. Long-term follow up of posterior vestibulectomy for treating vulvar vestibulitis. Acta Obstet Gynecol Scand 2011; 90: 1225-1231.

53 Helsinki Declaration. WMA Declaration of Helsinki-Ethical Principles for Medical Research Involving Human Subjects. 64th WMA General Assembly, Fortaleza, Brazil. 2013; www.wma.net/en/30publications/10policies/b3/ (last accessed 3 October 2016).

54 Feldhaus-Dahir M. The causes and prevalence of vestibulodynia: a vulvar pain disorder. Urologic Nursing 2011; 31: 51-54.

55 Fougner M, Haugstad GK. Treating gynecological pain: the experiences of bachelor students in physiotherapy performing somatocognitive therapy. Physiotherapy Theory \& Practice 2015; 31:318-326.

56 Piper CK, Legocki LJ, Moravek MB, Lavin K, Haefner HK, Wade K, et al. Experience of symptoms, sexual function, and attitudes toward counseling of women newly diagnosed with vulvodynia. J Low Genit Tract Dis 2012; 16: 447-453.

57 Haefner HK, Collins ME, Davis GD, Edwards L, Foster DC, Hartmann ED, et al. The vulvodynia guideline. J Low Genit Tract Dis 2005; 9: 40-51.

58 Eppsteiner E, Boardman L, Stockdale CK. Vulvodynia. Best Practice \& Research in Clinical Obstetrics \& Gynaecology 2014; 28: 1000-1012. 
Table 1 The Awareness and Knowledge of Vulvodynia and its Care (AKVDC) survey instrument

\begin{tabular}{|c|c|c|c|}
\hline \multicolumn{4}{|l|}{ AKVDC } \\
\hline $\begin{array}{l}\text { Part } 1 \\
\text { Awareness of VD and its care }\end{array}$ & Items & $\begin{array}{l}\text { Answering scale } \\
\text { A 6-point Likert scale }\end{array}$ & $\boldsymbol{\alpha}$ \\
\hline how to identify VD & 14 & & 0.83 \\
\hline & $\begin{array}{l}7 \\
7\end{array}$ & $\begin{array}{l}\text { from } 1=\text { completely disagree } \\
\text { to } 6=\text { completely agree } \\
\text { from } 1=\mathrm{I} \text { know it remarkably poorly } \\
\text { to } 6=\mathrm{I} \text { know it remarkably well }\end{array}$ & \\
\hline the treatments for VD & 13 & & 0.80 \\
\hline & $\begin{array}{l}7 \\
6\end{array}$ & $\begin{array}{l}\text { from } 1=\text { completely disagree } \\
\text { to } 6=\text { completely agree } \\
\text { from } 1=\mathrm{I} \text { know it remarkably poorly } \\
\text { to } 6=\mathrm{I} \text { know it remarkably well }\end{array}$ & \\
\hline the significance of & 15 & & 0.89 \\
\hline & $\begin{array}{l}11 \\
4\end{array}$ & $\begin{array}{l}\text { from } 1=\text { completely disagree } \\
\text { to } 6=\text { completely agree } \\
\text { from } 1=\mathrm{I} \text { know it remarkably poorly } \\
\text { to } 6=\mathrm{I} \text { know it remarkably well }\end{array}$ & \\
\hline $\begin{array}{l}\text { the significance of } \\
\text { providing information and } \\
\text { support to VD patients }\end{array}$ & 24 & $\begin{array}{l}\text { from } 1=\text { completely disagree } \\
\text { to } 6=\text { completely agree }\end{array}$ & 0.91 \\
\hline
\end{tabular}

\section{Part 2}

Items Answering scale

Knowledge about VD and its care 20 three options: true, false or unsure

VD: vulvodynia.

$\alpha$ : The Cronbach's alpha. 
Table 2 Characteristics of study participants $(n=79)$

\begin{tabular}{|c|c|c|c|}
\hline \multicolumn{2}{|l|}{ Demographic Variables } & \multirow{2}{*}{$\begin{array}{l}n \\
74\end{array}$} & \multirow{2}{*}{$\begin{array}{l}\% \\
93.7\end{array}$} \\
\hline Gender & Female & & \\
\hline & Male & 5 & 6.3 \\
\hline \multirow[t]{3}{*}{ Age } & $27-40$ & 25 & 31.6 \\
\hline & $41-53$ & 26 & 32.9 \\
\hline & $54-65$ & 28 & 35.4 \\
\hline \multirow{3}{*}{$\begin{array}{l}\text { Years of work experience } \\
\text { in health care }\end{array}$} & $1-14$ & 24 & 30.4 \\
\hline & $15-27$ & 28 & 35.4 \\
\hline & $28-40$ & 27 & 34.2 \\
\hline \multicolumn{4}{|l|}{ Education } \\
\hline \multicolumn{2}{|c|}{ Nursing and therapy staff } & 57 & \\
\hline & Public health nurse & 33 & 41.8 \\
\hline & Registered nurse & 4 & 5.1 \\
\hline & Psychologist & 11 & 13.9 \\
\hline & Physiotherapist & 4 & 5.1 \\
\hline & Other & 5 & 6.3 \\
\hline \multicolumn{2}{|c|}{ Physician staff } & 22 & \\
\hline & Physician & 22 & 27.8 \\
\hline \multirow[t]{3}{*}{ Type of job contract } & Regular & 68 & 86.1 \\
\hline & Fixed-term & 10 & 12.6 \\
\hline & Hourly & 1 & 1.3 \\
\hline \multirow[t]{2}{*}{ Specialization in sexology } & Yes & 11 & 13.9 \\
\hline & No & 68 & 85.1 \\
\hline \multirow[t]{2}{*}{ Attended lecture/s on VD } & Yes & 26 & 32.9 \\
\hline & No & 53 & 67.1 \\
\hline \multirow{5}{*}{$\begin{array}{l}\text { Frequency of meetings } \\
\text { with VD patients }\end{array}$} & Never & 14 & 17.7 \\
\hline & $<1 \mathrm{x}$ a month & 50 & 63.3 \\
\hline & $1-3 \times$ a month & 12 & 15.2 \\
\hline & $1 \mathrm{x}$ a week & 3 & 3.8 \\
\hline & $>1 \mathrm{x}$ a week & 0 & 0 \\
\hline \multirow{2}{*}{$\begin{array}{l}\text { Experienced-based skills in } \\
\text { taking care of VD patients }\end{array}$} & Poor (scale of $1-3$ ) & 60 & 75.9 \\
\hline & Good (scale of 4-6) & 19 & 24.1 \\
\hline \multirow{2}{*}{$\begin{array}{l}\text { Experienced-based skills in } \\
\text { taking care of VD couples }\end{array}$} & Poor (scale of $1-3$ ) & 64 & 81.0 \\
\hline & Good (scale of 4-6) & 15 & 19.0 \\
\hline \multirow{2}{*}{$\begin{array}{l}\text { Experienced-based skills in } \\
\text { naturally discussing intimate } \\
\text { issues }\end{array}$} & Poor (scale of $1-3$ ) & 36 & 45.6 \\
\hline & Good (scale of 4-6) & 43 & 54.4 \\
\hline
\end{tabular}

VD: vulvodynia. 

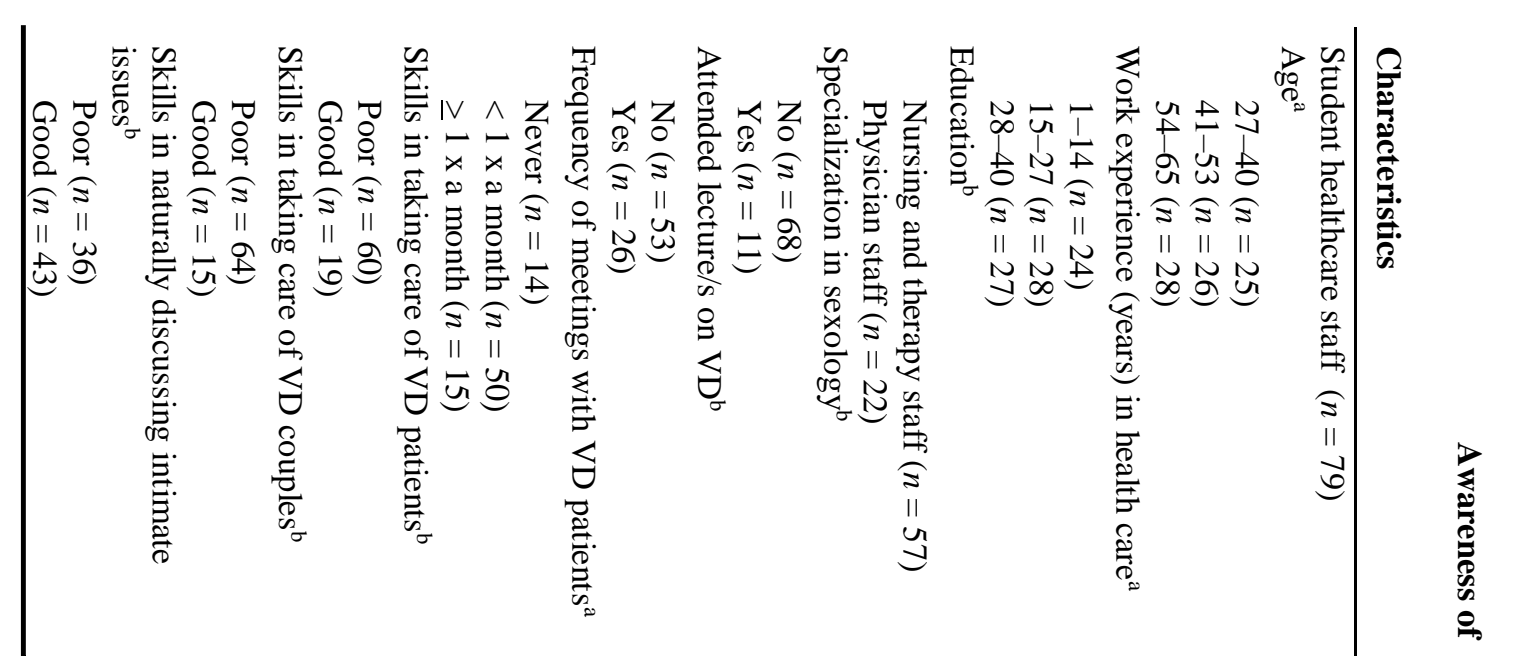

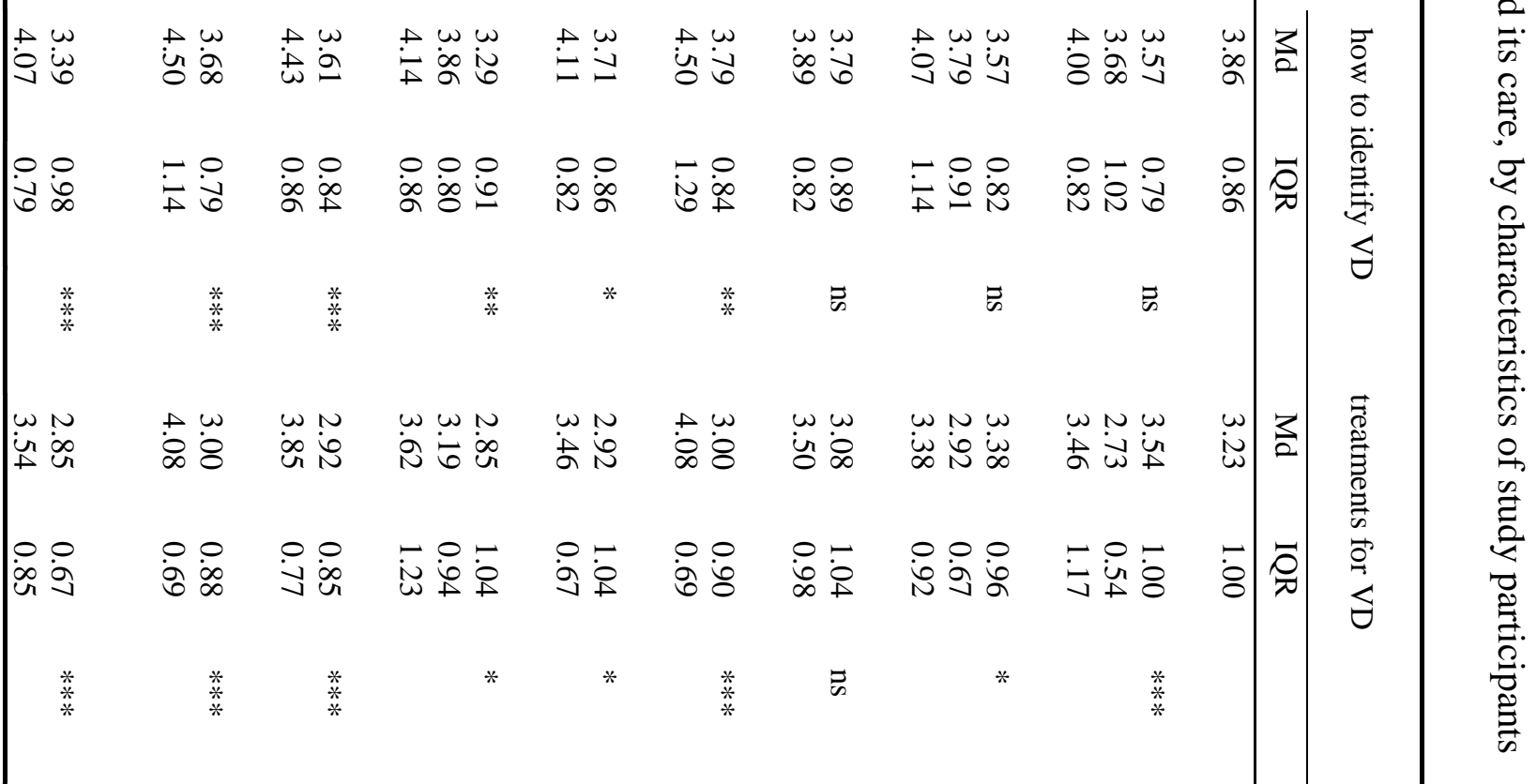

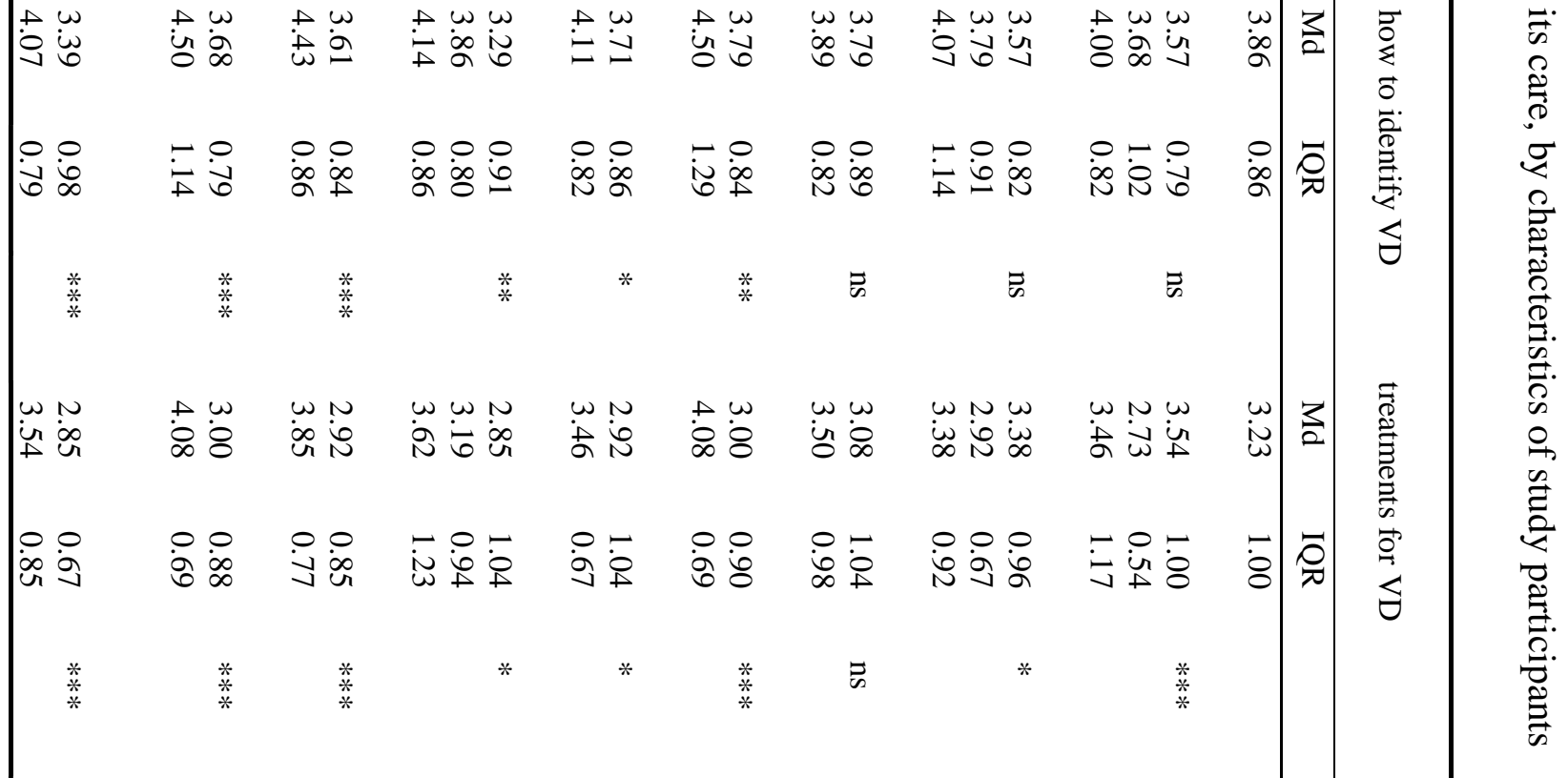

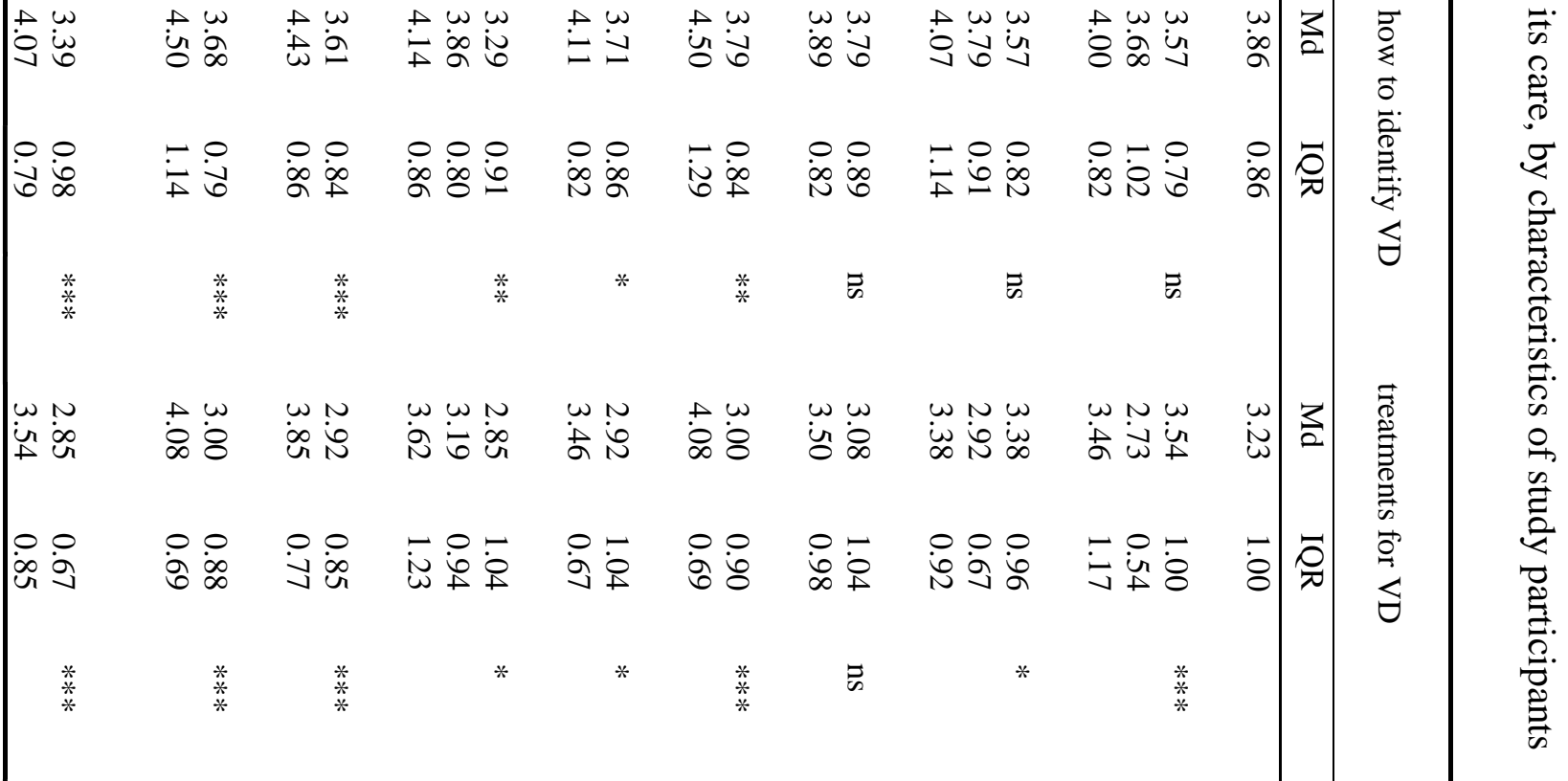

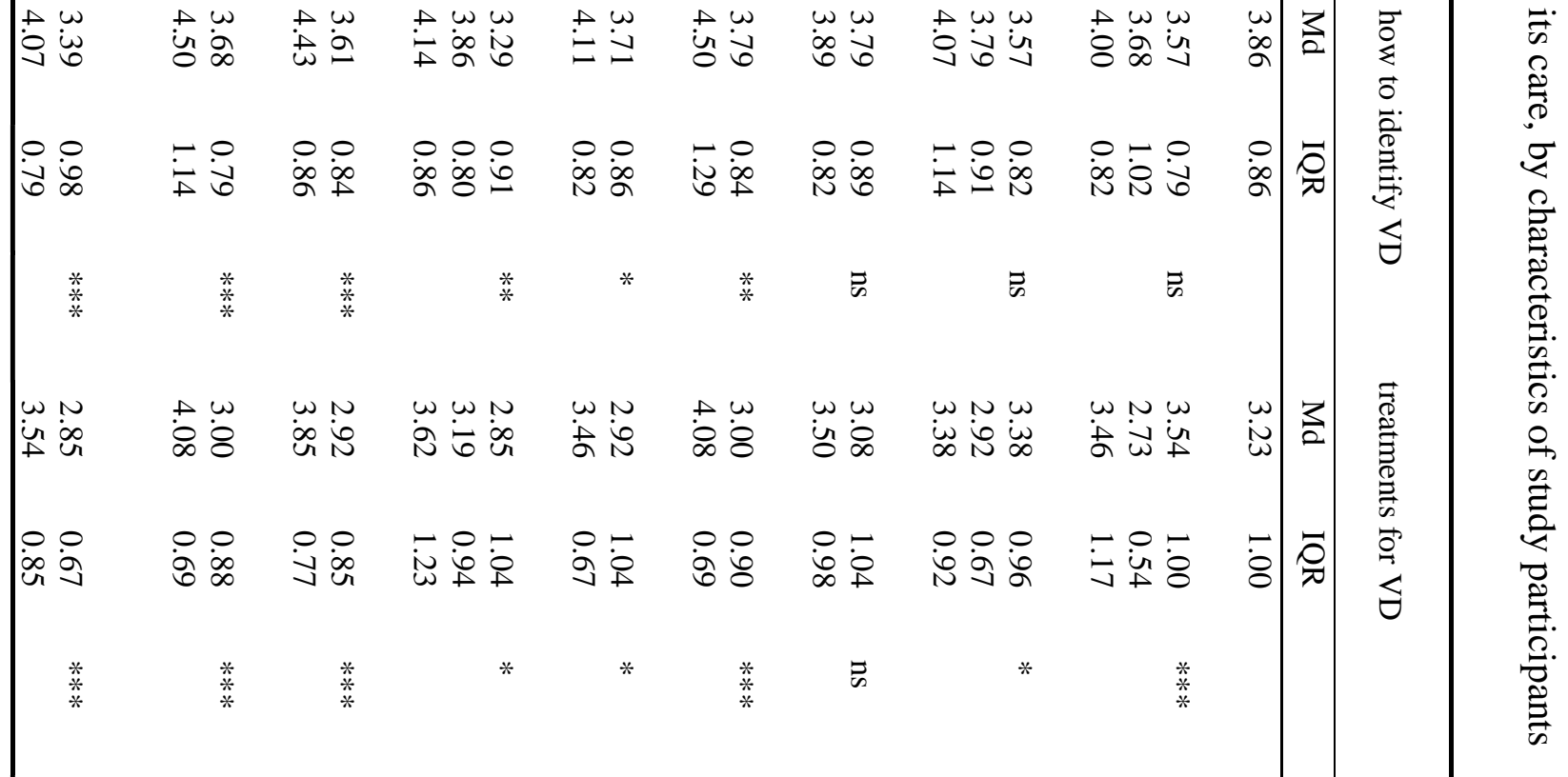

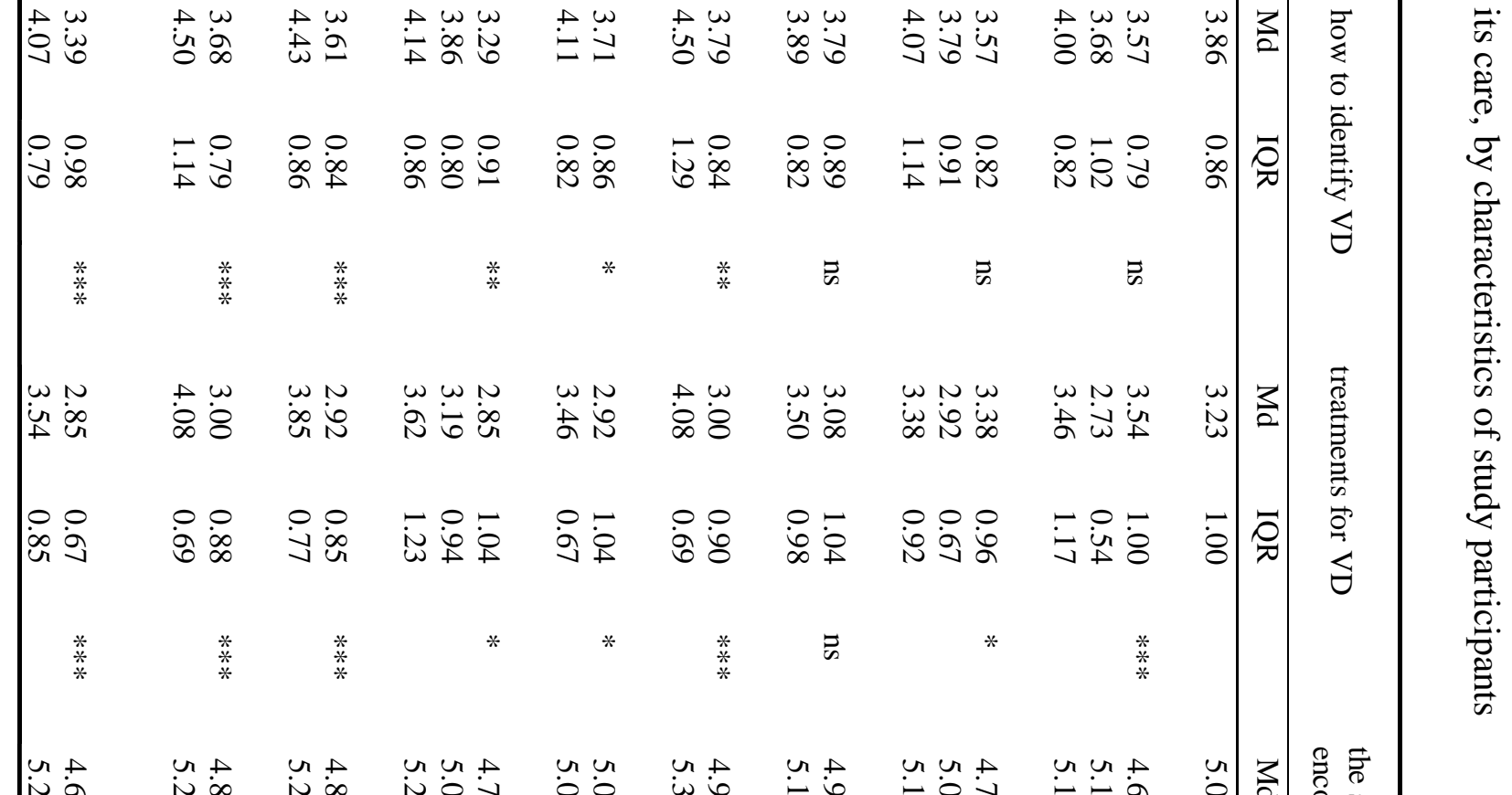

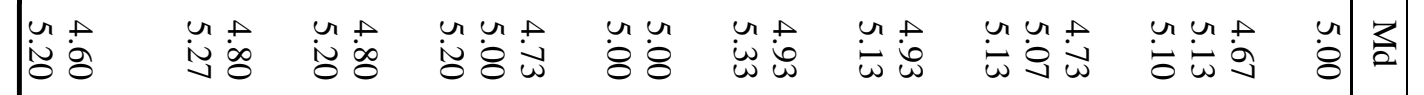

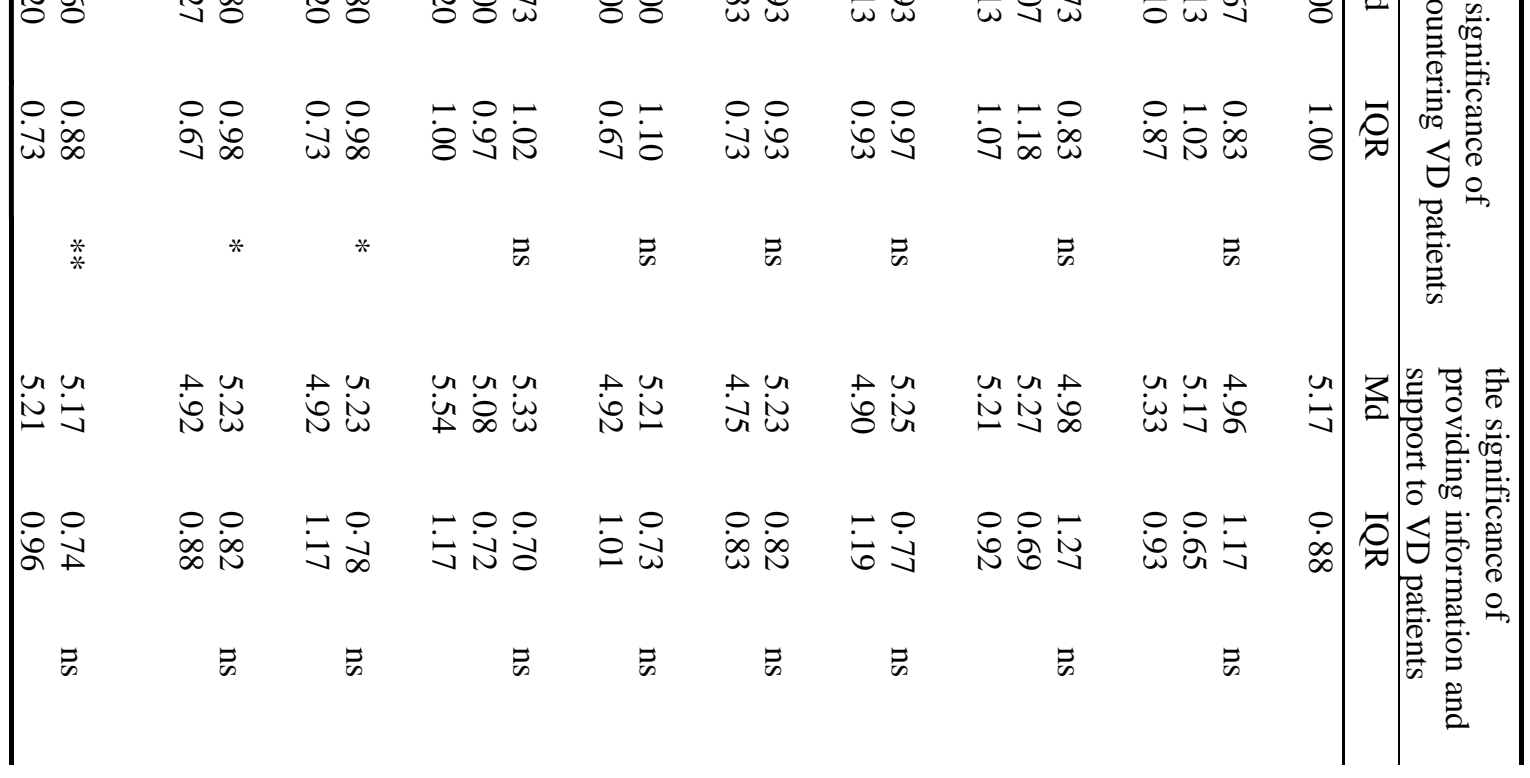

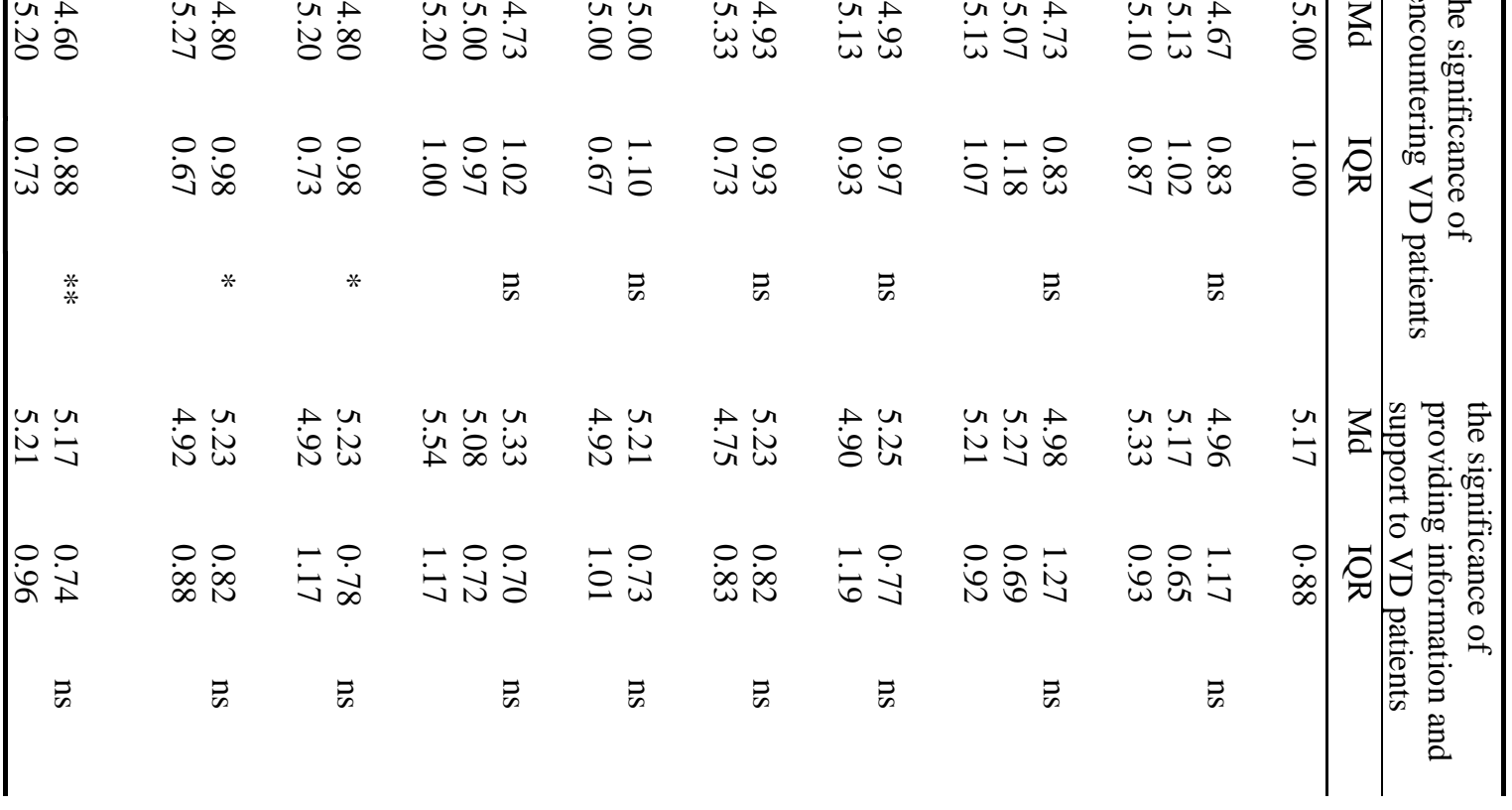

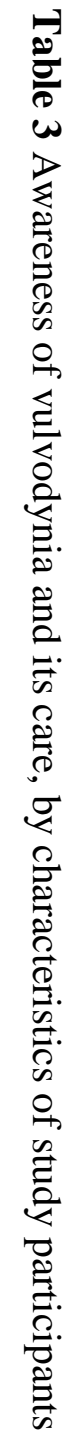


Table 4 Knowledge scores on vulvodynia (VD) and its care, by characteristics of study participants

\begin{tabular}{|c|c|c|c|c|c|}
\hline \multirow[b]{2}{*}{ Characteristics } & \multicolumn{5}{|c|}{ Knowledge of VD and its care } \\
\hline & Mean & Q1 & Q3 & $\mathrm{Md}$ & \\
\hline Student healthcare staff $(n=79)$ & 9.34 & 6.00 & 13.00 & 10.00 & \\
\hline \multicolumn{6}{|l|}{$\mathrm{Age}^{\mathrm{a}}$} \\
\hline $27-40(n=25)$ & 7.88 & 3.50 & 13.00 & 8.00 & $* *$ \\
\hline $41-53(n=26)$ & 8.35 & 5.50 & 12.25 & 9.50 & \\
\hline $54-65(n=28)$ & 11.57 & 9.00 & 15.00 & 13.00 & \\
\hline \multicolumn{6}{|l|}{ Work experience (years) in health care ${ }^{a}$} \\
\hline $1-14(n=24)$ & 8.04 & 3.25 & 13.00 & 8.00 & $*$ \\
\hline $15-27(n=28)$ & 8.46 & 5.25 & 11.75 & 9.00 & \\
\hline $28-40(n=27)$ & 11.41 & 9.00 & 15.00 & 13.00 & \\
\hline \multicolumn{6}{|l|}{ Education $^{\mathrm{b}}$} \\
\hline Nursing and therapy staff $(n=57)$ & 8.60 & 5.00 & 13.00 & 9.00 & $*$ \\
\hline Physician staff $(n=22)$ & 11.27 & 9.00 & 13.25 & 13.00 & \\
\hline \multicolumn{6}{|l|}{ Specialization in sexolog $y^{b}$} \\
\hline No $(n=68)$ & 8.79 & 5.00 & 13.00 & 9.00 & $*$ \\
\hline Yes $(n=11)$ & 12.73 & 10.00 & 15.00 & 13.00 & \\
\hline \multicolumn{6}{|l|}{ Attended lecture/s on $\mathrm{VD}^{\mathrm{b}}$} \\
\hline No $(n=53)$ & 8.30 & 4.00 & 13.00 & 9.00 & $*$ \\
\hline Yes $(n=26)$ & 11.46 & 9.00 & 14.25 & 12.00 & \\
\hline \multicolumn{6}{|l|}{ Frequency of meeting VD patients ${ }^{\mathrm{a}}$} \\
\hline Never $(n=14)$ & 6.36 & 0.00 & 9.25 & 5.50 & $* *$ \\
\hline$<1 \mathrm{x}$ a month $(n=50)$ & 9.18 & 6.75 & 13.00 & 9.50 & \\
\hline$\geq 1 \times$ a month $(n=15)$ & 12.67 & 11.00 & 15.00 & 12.00 & \\
\hline \multicolumn{6}{|l|}{ Skills in taking care of VD patients ${ }^{\mathrm{b}}$} \\
\hline Poor $(n=60)$ & 8.40 & 4.25 & 13.00 & 9.00 & $* *$ \\
\hline Good $(n=19)$ & 12.32 & 10.00 & 14.00 & 13.00 & \\
\hline \multicolumn{6}{|l|}{ Skills in taking care of VD couples ${ }^{b}$} \\
\hline Poor $(n=64)$ & 8.70 & 5.00 & 13.00 & 9.00 & $*$ \\
\hline $\operatorname{Good}(n=15)$ & 12.07 & 8.00 & 14.00 & 13.00 & \\
\hline \multicolumn{6}{|l|}{$\begin{array}{l}\text { Skills in naturally discussing intimate } \\
\text { issues }^{b}\end{array}$} \\
\hline Poor $(n=36)$ & 8.33 & 4.00 & 12.75 & 9.00 & ns \\
\hline Good $(n=43)$ & 10.19 & 7.00 & 13.00 & 12.00 & \\
\hline
\end{tabular}

Q1, Q3: Quartiles; Md: Median.

ns; not significant; $* p<.05 ; * * p<.01$.

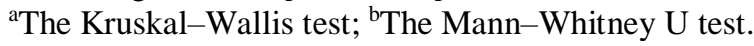

